\title{
ACESSO ÁS POLÍTICAS PÚBLICAS POR MULHERES TRABALHADORAS RURAIS DO MUNICÍPIO DE RETIROLÂNDIA-BA
}

\author{
Maria Carolina de Oliveira Silva ${ }^{1}$; Acácia Batista Dias ${ }^{2}$; Ildes Ferreira de \\ Oliveira $^{3}$
}

1. Bolsista PIBIC/FAPESB, Bolsista PIBIC/FAPESB, Graduanda em Psicologia, Universidade Estadual de Feira de Santana, e-mail: caroliina_002@hotmail.coom

2. Orientadora. Departamento de Ciências Humanas e Filosofia, Universidade Estadual de Feira de Santana, e-mail: acaciabatista02@gmail.com

3. Coordenador do Projeto Ser Tão Forte: Desenvolvimento Territorial

Sustentável, Departamento de Ciências Humanas e Filosofia, Universidade Estadual de Feira de Santana, e-mail:ildesferreira@ gmail.com

PALAVRAS-CHAVE: Políticas Públicas; Mulher; Trabalhadoras Rurais.

\section{INTRODUÇÃO}

Este estudo está vinculado ao projeto "SER TÃO FORTE: Desenvolvimento Territorial Sustentável” (CNPq/MDA/SPM-PR No 11/2014 - Núcleos de Extensão em Desenvolvimento Territorial - NEDET). O tema investigado refere-se à participação das mulheres nas organizações produtivas do município de Retirolândia/BA que através de um processo de politização contribui para a ressignificação do papel feminino, enquanto sujeito de direitos e a prática da cidadania, favorecendo um maior acesso às políticas públicas.

O município de Retirolândia, localizado no Território do Sisal possui uma área de 181, $461 \mathrm{~km}^{2}$ e uma população de aproximadamente 12.055 habitantes. O percentual de homens com 16 anos ou mais atuantes nas atividades de agricultura é igual a 40,5\%, já o percentual feminino atuante nesse setor, na mesma faixa etária, equivale a $29,2 \%$. O número da população economicamente ativa com 16 anos ou mais corresponde a 2.392 e 3.291 hab, para o sexo feminino e o sexo masculino, respectivamente (IBGE, 2010).

As agricultoras vivenciam uma condição de invisibilidade, muitas não possuem nenhuma renda e são tratadas pelos companheiros com discriminação (FIRMO, 2010). Situação que se agrava com o pouco acesso das mulheres rurais às políticas públicas.

Mesmo com a desigualdade de gênero presente no Território do Sisal, especificamente no município de Retirolândia, é perceptível uma significativa presença de associação e/ou grupos produtivos de mulheres, os quais possuem como objetivo alcançar reconhecimento, visibilidade, ampliar a participação na economia e combater as assimetrias de gênero.

Neste processo, destaca-se a presença do Movimento de Organização Comunitária (MOC), o qual tem um relevante papel no apoio e articulação de diversos movimentos sociais, incluindo suas ações na mobilização de mulheres presentes no sisal, responsável por despertar a sociedade civil para a questão de políticas públicas. (MOREIRA, 2017)

A pesquisa desenvolvida tem como objetivo publicizar as assimetrias de gênero em áreas rurais do município de Retirolândia, expressas através dos discursos das entrevistadas, demonstrando a conscientização das mesmas sobre a situação desfavorável na qual estão imersas e a forma que as organizações produtivas favorecem o acesso às políticas públicas e uma consequente busca da autonomia pessoal e financeira.

\section{MATERIAL E MÉTODOS}

Para a realização dessa pesquisa inicialmente buscou-se referências bibliográficas a respeito do tema, seguido da leitura, sistematização e análise das informações. A 
caracterização do município foi realizada através de dados secundários de fontes como Instituto Brasileiro de Geografia e Estatística (IBGE), Superintendência de Estudos Econômicos e Sociais (SEI), entre outras fontes.

Foi utilizado um mapeamento dos grupos produtivos de mulheres executado pela equipe NEDET Sisal. Após a identificação dos grupos, foi feito o contato com representantes dos mesmos e realizada as entrevistas semiestruturadas, através das quais foram coletadas informações históricas, geográficas, programas sociais direcionados à população rural e as políticas específicas acessadas pelas mulheres. Por fim, as entrevistas foram transcritas, sistematizadas e analisadas.

\section{RESULTADOS E/OU DISCUSSÃO}

O levantamento realizado no município de Retirolândia, com o apoio da equipe do Núcleo de Extensão em Desenvolvimento Territorial (NEDET) mapeou 10 grupos. Contudo, as entrevistas aconteceram com representantes de seis desses: Mulheres Nativas, Mulheres Inovadoras, Sabor Gama, Mulheres de Fé, Grupo do Beiju, Grupo Prosperar, além do Grupo Delícias da Gibóia. Em geral o surgimento dos grupos não foi uma demanda que emergiu especificamente das mulheres e sim por influência externa de organizações coletivas (cooperativas, MOC), através do fortalecimento de uma mentalidade associativista construindo um senso de coletividade, sentimento de pertença, confiança e solidariedade.

Durante as entrevistas, evidenciaram-se algumas semelhanças entre as integrantes dos grupos com relação às suas trajetórias e origem social. Muitas, antes de formação do grupo, já participavam de movimentos sociais: Na verdade, eu já participava dos movimentos sociais. É uma área que eu gosto muito e também eu fazia parte da Associação Comunitária Bastianense (...) porque a partir do momento que você se insere nesses empreendimentos solidários você acaba tendo uma autoestima elevada, você acaba aprendendo muito, aprende a ser mais solidária com o próximo. Porque quando você trabalha corporativismo, associativismo você acaba sendo mais humano. (J. L, 30 anos, ensino superior incompleto, Grupo Prosperar).

Em geral, a inserção das mulheres no grupo de produção ocorre por motivos financeiros, representando para as mesmas uma oportunidade de geração de renda, além da flexibilidade de horários que permite a conciliação com outras atividades. Segundo Siliprandi e Cintrão (2011), a escolha da realização destes tipos de práticas produtivas está relacionada com o exercício de atividades que podem ser realizadas nos intervalos de outras obrigações e que não exigem, pelo menos de imediato, investimentos financeiros conforme demonstrado a seguir: É uma oportunidade de emprego, é uma renda extra. Ás vezes a gente trabalha, mas é em outras coisas, em casa de família e tal. E aí é uma coisa que você pode fazer em seu momento livre, é diferente de casa de família. (J.L, 26 anos, ensino fundamental incompleto, Grupo Delícias da Gibóia).

Para além do aspecto financeiro, o grupo funciona como um meio através do qual as mulheres alcançam determinada autonomia e liberdade, já que muitas estavam aprisionadas ao seu espaço privado, além de contribuir na aprendizagem, na elevação da autoestima e no sentimento de representatividade de grupo, como foi demonstrado por uma das entrevistadas: Quando o grupo foi unificado, tinha mulheres que não podiam sair de casa, os maridos não deixavam. Mas, a partir do momento que ela começou a participar dessas discussões, que havia muitos debates, muitos discursos, elas começaram a enfrentar os maridos. Elas conseguiram sair de casa, vim pra as reuniões, vim trabalhar. (J.L, 30 anos, ensino superior incompleto, integrante do Grupo Prosperar )

Vale ressaltar ainda que através da participação nas organizações coletivas e movimentos, as mulheres conseguem expressar suas opiniões, manifestar suas necessidades e angústias diante das desigualdades que vivenciam, ter acesso a informação, conhecer seus 
direitos, o que lhes proporciona assunção de posicionamentos políticos por direitos: Através desses grupos as mulheres começaram a se ingressar mais nos espaços sociais, a conhecer os seus direitos, a lutar por eles.(J.S,30 anos,ensino superior incompleto, Grupo Prosperar)

Apesar dos benefícios proporcionados pelas organizações produtivas, ressalta-se a condição desigual que muitas mulheres rurais ainda vivenciam, principalmente no contexto da agricultura familiar. Butto et al (2011) acrescentam que enquanto os homens assumem atividades econômicas que geram emprego, ocupação e renda, as mulheres concentram-se em atividades direcionadas para o autoconsumo familiar, com baixos salários. No entanto, a participação dentro das organizações produtivas tem proporcionado um avanço no aprofundamento da discussão das relações de gênero e do papel feminino dentro das famílias e na sociedade contribuindo para uma conscientização das integrantes e questionamentos sobre a invisibilidade política, econômica e social as quais estão historicamente submetidas, como nos demonstra A.A (60 anos, ensino médio completo, Grupo Sabor Gama): Quando a gente participa desses debates a gente começa a entender nossos direitos, a buscar por eles. Porque não é só o homem que tem direito né? A gente mulher também tem.

Diante desse cenário desigual e por meio da atuação através de organizações e movimentos, as mulheres mobilizadas têm conseguido interferir na agenda pública e adquirir legitimidade junto á sociedade e ao Estado, que busca incluir algumas de suas propostas nos espaços institucionais.

Além disso, é através dessas políticas que as mulheres rurais podem garantir uma renda mensal, contribuindo para reverter à condição de invisibilidade feminina e alcançar uma consequente autonomia. Entretanto, as entrevistadas informam acesso e/ou conhecimento de poucas políticas e/ou programas, como Bolsa Família, PNAE e PAA. No que diz respeito às políticas específicas para as mulheres rurais, a situação não foi diferente, as mulheres demonstraram não conhecer tais políticas, conforme salientado por J.S (26 anos, ensino fundamental incompleto, integrante do grupo Delícias da Gibóia): Não, não sabemos nem o que é. Tem pelo sindicato, um grupo de mulheres, mas não tem muito acesso não.

No que se refere, a forma como recebem informações sobre essas políticas públicas a maioria das mulheres enfatizaram nos seus discursos a participação efetiva do MOC, que atua desde a capacitação, até a elaboração e implementação dessas políticas, como nos conta G.L (31 anos, ensino superior completo, Grupo Mulheres Inovadoras): Aí só através do pessoal, como por exemplo o MOC hoje. Hoje, é o MOC quem tem mais essa preocupação de tá passando pra as pessoas as políticas. Apesar da atuação dessa entidade ter proporcionado um considerável avanço no acesso as políticas públicas, as mulheres consideram essas políticas ainda insuficientes, quando comparado aos anos anteriores e denunciaram o comodismo e o pouco envolvimento das participantes, como prováveis motivos para o insuficiente acesso a essas políticas: Eu acho que pode ser comodismo, o não procurar se informar, procurar saber quais as políticas além das que elas acessam elas tem o direito de acessar,quais as que estão disponível. (J.L, 30 anos, ensino superior incompleto, Grupo Prosperar).

Assim, de acordo com Pires (2016, para além dessas políticas públicas é fundamental elaborar ações que as dinamizem, contribuindo para a plena participação da sociedade civil representada, a fim de alcançar os objetivos almejados. Não cabe ao governo uma responsabilidade única na elaboração e avaliação destas políticas, é fundamental que toda a sociedade esteja atenta e inserida no processo, por se tratar de uma intervenção social que atinge a todos. Sem conhecer as políticas e suas diretrizes, o indivíduo permanece excluído, levando em conta que o governo é constituído por grupos sociais que buscam executar seus interesses, nem sempre dispostos a considerar outras categorias. 


\section{CONSIDERAÇÕES FINAIS}

No processo de pesquisa tornou-se perceptível que as organizações coletivas propiciam para as mulheres avanços em relação à invisibilidade política, social e econômica, incentivo a autonomia, determinado reconhecimento pessoal, elevação da autoestima. Além de favorecer o processo de sociabilidade, contribuir para a ressignificação do papel feminino, enquanto sujeito de direitos, para a prática da cidadania e consequentemente um maior acesso às políticas públicas. No entanto, apesar alguns avançados, ainda são incipientes a participação delas nos programas sociais. principalmente no que se refere àqueles específicoas para as mulheres, sendo as únicas relatadas: o ATER MULHER e o PRONAF MULHER. Esse pouco acesso foi motivado basicamente pela falta de informações sobre seus direitos, que colocam as mulheres a mercê dos interesses políticos se tornando uma barreira na mudança da lógica hegemônica de poder e de hierarquia que nutre as desigualdades. Assim, faz-se necessário a inserção de toda a sociedade civil no processo de elaboração e execução das políticas públicas, além da ampliação de espaços que torne cada vez mais público as desigualdades de gênero existentes e contribua para um processo de conscientização coletiva da sociedade em geral.

\section{REFERÊNCIAS}

BUTTO, A. 2011. Política para as Mulheres Rurais: autonomia e cidadania. In: BUTTO, Andrea; BORDALO, C; JALIL. L. SILIPRANDI, E; FARIA. N; BRUNO, R; WEITZMAN, R; CINTRÃO, R; SPANAVELLO, R.M; AQUINO, S.L; JUNIOR, V. J.W. Autonomia e cidadania: políticas de organização produtiva para as mulheres no meio rural.Brasília,p1-194.

FARIA, N; SILVEIRA, M.L. 2005. Feminismo e Luta das Mulheres: Relações de gênero e agricultura familiar. Sempreviva Organização Feminista - SOF. São Paulo. p 5-67 FIRMO, C. S. Desenvolvimento Territorial Sustentável e Gênero:o caso do território Sisaleiro da Bahia. Universidade Federal de Minas Gerais, Monografia. [Online]

Instituto Brasileiro de Geografia e Estatística (IBGE), IBGE CIDADES @. 2010. http://cidades.ibge.gov.br/xtras/perfil.php?lang=\&codmun=292610\&search=bahia|retirolandia MOREIRA, O. M. "Lugar de Mulher é onde ela Quiser". Universidade Estadual de Feira de Santana, Dissertação. PIRES, S. M. A atuação da Associação de Mulheres Trabalhadoras Rurais no Contexto das Políticas de Segurança Alimentar e a Constituição de Novas Territorialidades em Santa Luz- BA. Universidade Estadual de Feira de Santana, Dissertação.

SILIPRANDI, E. 2011. Pobreza Rural, agricultura e segurança alimentar: os muitos caminhos do empoderamento das mulheres. In: Sessão da Comissão Sobre o Status das Mulheres (CSW) DA UN WOMEN, 55. 2011, Nova York. Artigo. Nova York: Edição Especial da Revista do Observatório Brasil da Igualdade de Gênero, 2012. v. 1. 